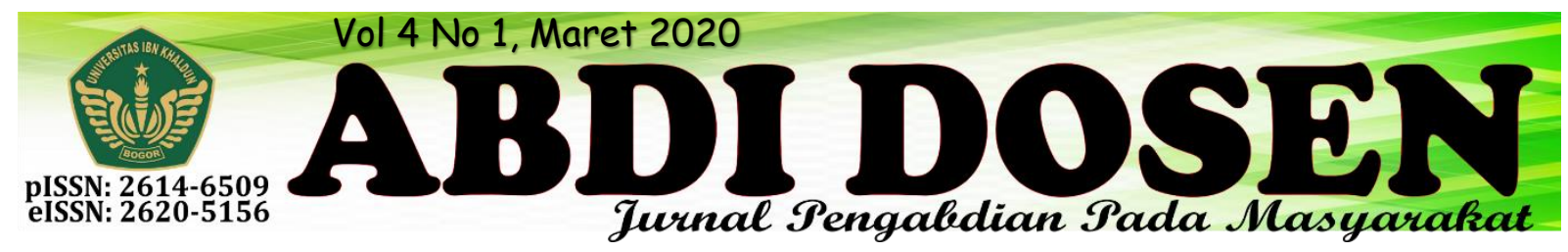

\title{
MEMBANGUN MASYARAKAT DESA BANYUWANGI DALAM MENINGKATKAN SUMBER DAYA MANUSIA MENUJU DESA YANG KRATIF DAN INOVATIF
}

\author{
Muhammad Fahri ${ }^{1}$, Desmy Riani ${ }^{2}$, Dendy Murdani ${ }^{3}$ \\ fahri@fai.uika-bogor.ac.id ${ }^{1}$ \\ desmy@uika-bogor.ac.id ${ }^{2}$
}

Dosen Agama Islam Islam¹, Dosen Fakultas Ekonomi dan Bisnis², Mahasiswa KKN Kelompok $59 \& 60$ Tahun $2019^{3}$

\begin{abstract}
ABSTRAK
KKN Tematik Terintegrasi merupakan KKN yang orientasi program terfokus pada bidang tertentu sesuai dengan permasalahan kemasyarakatan dan arah kebijakan pembangunan yang diselenggarakan pemerintah pada wilayah tertentu (Kabupaten/Kota). KKN memiliki tujuan untuk mencapai ekselerasi dan efektivitas program pembangunan yang ditandai dengan semakin baiknya kualitas kehidupan masyarakat, partisipasi dan eksistensi masyarakat dalam program-program pembangunan. Kegiatan KKN dibagi menjadi beberapa tahap, yaitu survey dan observasi ke desa sasaran, workshop, pendekatan sasaran program, realisasi program, monitoring dan evaluasi kegiatan, dan lokakarya hasil KKN. Pelaksanaan KKN dimulai dari tanggal 7 Agustus 2019 sampai dengan 5 September 2019 di Desa Banyu Wangi Kecamatan Cigudeg Kabupaten Bogor. Program KKN kelompok 59 dan 60 di Desa Banyu Wangi merupakan program yang lebih menekankan kepada kualitas sumber daya manusia. Kegiatan fisik kelompok 59-60. yaitu pemberian dan pemasangan Gapura, Pengecatan Mushola, Penyediaan Air Bersih, Pengadaan Taman Baca dan Penerangan Jalan. Dan kegiatan non fisik kelompok 59 dan 60 antara lain pendampingan Posyandu, penyuluhan kesehatan (PHBS, CTPS dan Hipertensi disertai pemeriksaan tensi gratis), Kegiatan Mengajar di dalam Posko, SD dan MTS ,Pelatihan Microsoft Word Dan Simulasi UNBK di SMP dan SMA sederajat, kegiatan Mengaji, Bimbel, pelaksanaan kegiatan TPA, lomba 17 agustus, dan acara perpisahan KKN di Kampung dan Kantor Desa.
\end{abstract}

\section{Kata Kunci : KKN, Banyu Wangi, Program KKN.}

\section{PENDAHULUAN}

\section{Analisis Situasi}

Berdasarkan hasil observasi dan analisis yang kelompok kami lakukan di Desa Banyu Wangi Kecamatan Cigudeg Kabupaten Bogor - Jawa Barat. Desa Banyu Wangi memiliki luas wilayah 514.000.000 ha. Dengan batas wilayah sebagai berikut :

Sebelah Utara: Banyu Asih

\section{Sebelah Selatan: Batu jajar}

Sebelah Timur: Leuwisadeg

Sebelah Barat: Banyu Resmi

Memiliki 4 Dusun yang terdiri dari dusun 1, dusun 2 dusun 3 dan dusun 4 . Banyu Wangi memiliki suhu yang cukup Sejuk, jumlah penduduk keseluruhan Desa Banyu Wangi adalah 8.881 jiwa. Secara umum dapat dijelaskan bahwa penduduk 
Banyu Wangi bermata pencaharian Petani, wiraswasta, Buruh dan selebihnya mempnyai mata pencaharian yang bervariasi.

Cukup rendah nya tingkat kesejahteraan masyarakat menjadi penyebab timbulnya beberapa masalah dengan beberapa bidang di Desa Banyu Wangi, diantaranya bidang ekonomi, kesehatan, lingkungan dan pendidikan. Hal tersebut disebabkan oleh ketidak berdayaan masyarakat desa karena kurangnya ilmu pengetahuan.

\section{Permasalahan yang dihadapi}

1. Kurangnya perhatian orangtua terhadap pendidikan anaknya

2. Kurangnya sarana dan prasarana pendidikan di Desa Banyu Wangi dalam membantu pembelajaran siswa

3. Kurangnya kesadaran masyarakat akan pentingnya Kebersihan Sehingga timbulnya pembuangan sampah sembarangan.

4. Pengelolaan Potensi tempat wisata yang belum dikelola dengan baik

5. Penerangan jalan yang belum memadai

6. Tidak adanya jaringan seluler di Desa Banyu Wangi

7. Kurang meleknya warga terhadap teknologi

8. Tidak adanya air bersih dan sumber mata air yang belum di kelola

\section{Solusi Yang di Tawarkan}

Setelah memahami beberapa permasalahan yang terjadi di Desa Banyu Wangi, maka kami menawarkan beberapa solusi yang terbaik untuk membantu memajukan desa Banyu Wangi, solusisolusi tersebut diantaranya :

1. Adanya program mengajar di sekolah sekolah sekitar desa banyu wangi yaitu di SDN banyu resmi 02, SDN cikaung
01 dan, di Madrasah diniyah Al-Husni

2. Adanya program bimbingan belajar kepada anak-anak dalam membantu menyelesaikan pekerjaan rumah dari sekolah dan memberikan pengetahuan tambahan kepada anak-anak.

3. Adanya program bimbingan belajar kepada anak-anak sekolah dasar di Kampung Monggor Kemang Sekitar Posko KKN dan memberikan pengetahuan tambahan kepada anak- anak.

4. Adanya program bimbingan mengaji kepada anak-anak dalam membantu pembacaan huruf Hijaiyah dan pengetahuan agama lainnya sepeti cara berwudhu dan lain-lain.

5. Adanya program taman baca yang didirikan di Kp Monggor Kemang, tidak lain hanya dilakukan agar mempermudah anak-anak di Desa Banyu Wangi menambah ilmu dan wawasan baru diluar sekolah.

6. Adanya program penyuluhan kesehatan, Pemberian Vitamin untuk balita, diseratai adanya pemeriksaan hipertensi terhadap warga .

7. Adanya program dalam pelaksanan HUT RI ke 74 di kp. Cikaung dan Di SDN Banyu Resmi 02.

8. Adanya program tabungan usia dini untuk anak-anak di KP. Monggor Kemang

9. Memberikan pelatihan tentang pembuatan kue dan makanan, untuk usaha kecil menengah.

10. Adanya program air bersih bekerjasama dengan PDAM Lewiliang untuk warga sekitar Desa Banyu Wangi.

11. Adanya program penerangan jalan umum (PJU) di sekitar Kp. Monggor Kemang. 


\section{METODE PENGABDIAN}

Tahapan pelaksanaan untuk kegiatan ini sebagaimana terlihat pada bagian sebagai berikut :

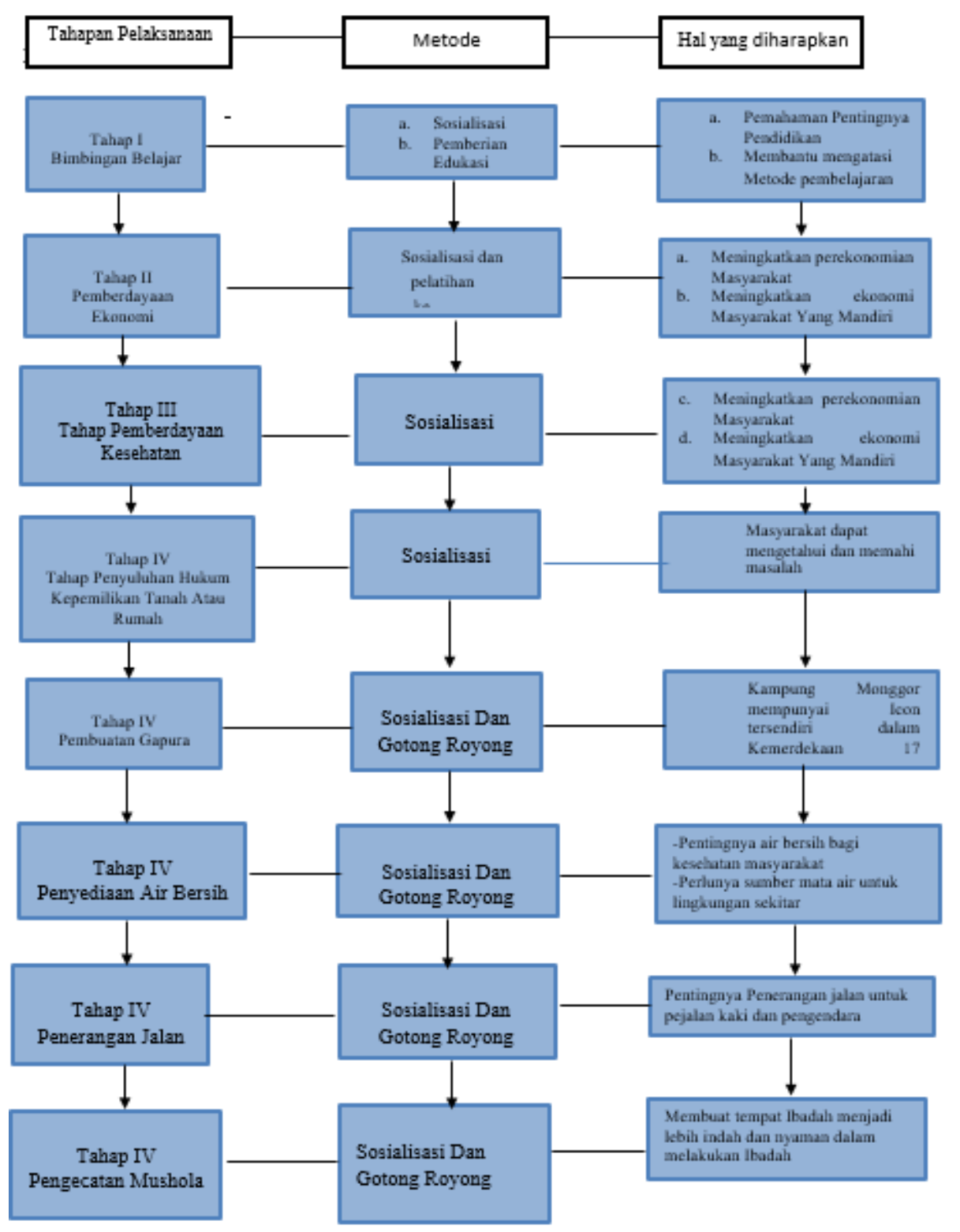

\section{Metode Pendekatan}

Ada beberapa pendekatan yang dilakukan kami demi kelancaran program kerja selama 1 bulan di Desa Banyu Wangi, pendekatan tersebut diantaranya :

\section{Pendekatan Organisasi}

Organisasi merupakan hal yang dimilki peran penting ditengah-tengah masyarakat. Pendekatan organisasi dilakukan untuk mempermudah pengenalan kami kepada warga desa Banyu Wangi.

\section{Pendekatan Religius}

Pendekatan religius yang dimaksud adalah pendekatan dengan cara bergabung ke dalam Pengajian Rutin bapak-bapak. Pendekatan religius ini dianggap perlu dilakukan didesa Banyu Wangi.

3. Pendekatan Masyarakat

Pendekatan masyarakat yang dimaksud adalah memahami kebiasaan warga desa Banyu Wangi dan mengikuti situasi di desa Banyu Wangi sehingga dapat 
mempermudah terealisasikannya program kerja yang telah kami rencanakan.

4. Pendekatan Edukasi

Desa Banyu Wangi memiliki masyarakat yang memiliki latar belakang yang berbeda-beda. Tidak semua masyarakat mempunyai pengetahuan yang lebih modern dalam menjalankan kehidupan sehari-hari di lingkungannya. Maka dari itu pendekatan edukasi sangatlah di perlukan untuk mempermudah pendekatan dan pengenalan program kami kepada warga.

\section{Langkah Evaluasi}

Evaluasi yang akan dilakukan terdiri dari :

\section{HASIL DAN PEMBAHASAN}

\section{Bidang Ekonomi}

\section{Kewirausahaan}

Tujuan :

- Meningkatkan pembelajaran Ibu-Ibu untuk pembuatan resep Donat karakter dan Kentang kriwil di desa mongor kemang

- Melatih Ibu-ibu untuk melakukan usaha sendiri atau bersama

- Membantu Ibu-Ibu untuk memperoleh manfaat dari keuntungan

- Mendemontrasikan potensi secara penuh

- Membudayakan semangat wirausaha di masyarakat

- Memberikan kesempatan kepada setiap Ibu-ibu untuk menumbuhkan keprbadian berwirausaha

- Untuk memanfaatkan waktu kosong agar menjadi lebih bermanfaat

- Membina dan mengembangkan Ibu-ibu untuk mengikuti perkembangan ilmu pengetahuan baru
1. Evaluasi proses yang terkait dengan perencanaan, pelaksanaan dan monitoring kegiatan. Evaluasi proses akan dilakukan di setiap kegiatan secara internal.

2. Evaluasi hasil, yang akan dilakukan setelah kegiatan dilaksanakan. Evaluasi hasil di tunjukan untuk menguji pemahaman masyarakat tentang pentingnya pendidikan $100 \%$ bisa tercapai. Selain itu, evaluasi hasil akan ditunjukan pada terciptanya lingkungan bersih dan terbangunnya literasi dengan target $80 \%$ bisa tercapai.

\section{Tabungan Usia Dini}

Tujuan :

- Mengajari anak-anak untuk mengelola keuangan

- Mengenalkan perbankan melalui tabungan

- Menjadikan Anak-anak memiliki kebiasaan menabung

\section{Bidang Pendidikan Dan Keagamaan}

\section{Pendidikan}

Tujuan :

- Membantu Kegiatan belajar mengajar di Sekolah

- Mempererat ukhuwah Islamiyah dengan pihak sekolah yang ada di Desa Bany Wangi

- Mengetahui potensi akademik anak di Desa Banyu Wangi

\section{Menggajar di TPA}

Tujuan :

- Meningkatkan kemampuan dalam membaca iqro, al-qur'an, hafalan surat - surat pendek dan Asmaul Husna. 
- Meningkatkan ukuwah islamiyah diantara tim KKN dengan anak-anak Kp.Monggor Kemang.

\section{Bimbingan Belajar}

Tujuan :

- Memberikan pelajaran tambahan yang bertempat di posko KKN

- Memberikan bantuan kepada anakanak untuk mengerjakan PR dari guru

- Membantu anak yang mengalami kesulitan dalam belajar

4. Mengajar di Madrasah Diniyah AlHusni

Tujuan :

- Membantu kegiatan Kegiatan belajar mengajar di madrasah

- Membantu meningkatkan keterampilan dalam membuat kaligrafi,bahasa Arab, akidah dan fiqih

\section{Pawai Obor 1 Muharram}

Tujuan :

- Partisipasi dalam memperingati Tahun Baru Islam (Muharram)

- Mempererat ukhuwah islamiyah dengan masyarakat Desa Banyu Wangi

- Meningkatkan cinta terhadap Agama Islam

\section{Bidang Teknik}

1. Pembuatan gapura dan pemasangan penunjang kegiatan 17 agustus

Tujuan :

- untuk memeriahkan hari kemerdekan indonesia

- sebagai gerbang selamat datang kampung monggor kemang

- sebagai tanda kampung monggor kemang

2. pembangunan penerangaan jalan

(PJU) di desa banyuwangi kampung monggor kemang

Tujuan :

- untuk memeriahkan hari kemerdekan indonesia
- sebagai gerbang selamat datang kampung monggor kemang

- sebagai tanda kampung monggor kemang

- untuk membantu warga kampung monggor kemang buat masalah penerangan

- jalan menjadi terang dan warga merasa nyaman

\section{Pengecatan Mushola}

Tujuan :

- Untuk menjadikan tempat ibadah yang nyaman

\section{Ngaji Teknologi}

Tujuan:

- Memberikan Wawasan Pengetahuan Teknologi di kampong Monggor Kemang

5. Pelatihan MS Word Dan Simulasi UNBK

Tujuan :

- Memberikan Pengetahuan dan Keahlian Aplikasi Microsoft Word Dan latihan simulasi Ujian Nasional Berbasis Komputer

\section{Bidang Kesehatan}

1. Penyuluhan Stunting di Posyandu Cikawung, Cirangsad, dan Kembang Wangi beserta kegiatan pemberian Vitamin A untuk bayi dan balita. Pada tanggal 9, 13, dan 16 Agustus 2019.

Tujuan umum :

- Memberi pengetahuan tentang stunting pada anak dan cara mencegahnya.

Tujuan khusus :

- Menjelaskan tentang pengertian Stunting

- Mengerti tanda dan gejala stunting

- Mengerti penyebab Stunting

- Mengerti Faktor yang mempengaruhi terjadinya stunting

- Mengerti Dampak stunting 
- Mengerti pencegahan stunting pada anak

- Mengerti penanggulangan stunting pada anak

2. Penyuluhan Hipertensi dan Cek Kesehatan (Tensi Darah) di kampung Monggor Kemang. Pada tanggal 23 Agustus 2019.

Tujuan :

- Mengetahui pengertian Hipertensi.

- Mengetahui Gejala Tekanan darah tinggi :.

- Mengetahui Etiologi hipertensi

- Mengetahui Penyebab Tekanan darah tinggi

- Mengetahui Apa yang harus dilakukan jika mengalami TEKANAN DARAH TINGGI?.

- Mengetahui Komplikasi hipertensi

\section{Bidang Hukum}

\section{Seminar Hukum}

Kegiatan ini dilaksanakan di aula kecamatan Cigudeg Tanggal 24 Agustus 2019 jam 10.00 di hadiri oleh 69 peserta

\section{KESIMPULAN}

Berdasarkan hasil kegiatan, pengamatan, maupun pelaksanaan program kerja KKN yang telah direncanakan, disusun dan dilaksanakan. Maka kelompok 59 dan 60 KKN UNIVERSITAS IBN KHALDUN BOGOR 2019 di Desa Banyu Wangi Kecamatan Cigudeg mengambil beberapa kesimpulan yaitu :

1. Keberhasilan KKN tidak lepas dari kerja sama antara mahasiswa dengan perangkat desa,masyarakat,serta semua pihak yang membantu dan mendukung terlaksananya kegiatan KKN tanpa adanya kerja sama yang baik, program kerja KKN tidak akan berjalan dengan lancar.

2. Dengan adanya mahasiswa $\mathrm{KKN}$ masyarakat terbantu dengan dari kalangan ibu-ibu PKK, tokoh masyarakat,Polsek Cigudeg, KNPI dan mahasiswa yang sedang KKN di Kecamatan Cigudeg. Kegiatan ini bertema yaitu "Membangun kesadaran hukum terhadap perlindungan anak dan pemberdayaan perempuan "Kegiatan ini bertujuan untuk memberi pemahaman hukum kepada warga desa sekecamatan cigudeg terhadap anak dan perempuan atas kasus yang terjadi berbagai desa yaitu adanya KDRT dan hamil diluar nikah. Pentingnya sosialisasi UU Perlindungan anak.

Simpulan:

Berdasarkan hasil evaluasi,pengamatan dan tanggapan langsung dari peserta kegiatan penyuluhan ini cukup baik mengingat adanya peningkatan pemahaman mengenai pentingnya sosialisasi Undang-undang perlindungan anak dan pemberdayaan perempuan. Serta partisipasi dan respon positif dari peserta menghasilkan interaksi yang menarik.

bertambahnya informasi dan ilmu pengetahuan yang mereka peroleh dari mahasiswa KKN.

3. Kurangnya kepedulian masyarakat desa terhadap lingkungan sekitar

4. Potensi desa di Desa Banyu Wangi II telah dikelola cukup baik oleh masyarakat, sehingga tercapai hasil yang cukup memuaskan, diantaranya :

a. Kerjasama yang baik antara masyarakat, perangkat desa serta instansi terkait guna memperlancar pembangunan desa.

b. Keterbukaan aparat desa terhadap masyarakat, mampu menjalin hubungan komunikasi yang baik.

Dengan demikian, hasil kesimpulan di atas menunjukan bahwa secara garis 
besar program KKN kelompok 59 dapat dikatakan sukses dan lancar meskipun ada beberapa kendala baik dari pihak mahasiswa maupun pihak masyarakat di Desa Banyu Wangi namun itu tidakberpengaruh terhadap program yang telah direncanakan.

\section{Dampak Bagi Masyarakat}

Dalam program-program kerja yang akan laksanakan dampak yang dapat diperoleh masyarakat antara lain :

\section{Bidang Pendidikan}

a. Bimbingan Belajar

Manfaat penyelenggaraan bimbingan belajar ini adalah anak-anak dapat termotivasi untuk melanjutkan pendidikanya kejenjang yang lebih tinggi, juga membantu anak-anak mendapatkan ilmu yang lebih selain di sekolah. Membantu anak dalam mengerjakan PR. Anak- anak juga mendapat metode dan system pengajaran yang berbeda dengan di sekolah. Selain itu anak-anak dapat meningkatkan kemampuan dalam menghaapi kesulitan dalam memahami pelajaran.

b. Pengajian Anak-anak

Manfaat yang diperoleh yaitu agar pendidikan agama khususnya cara membaca al-quran yang baik dan benar dengan mengetahui hukum tajwidnya kepada anak-anak di lingkungan.

2. Bidang Kesehatan

a. Membantu Posyandu

Kegiatan ini bermanfaat untuk mahasiswa itu sendiri karena ilmu yang telah di dapat dalam perkuliahan bisa di aplikasikan disana, seperti: Mengecek Tensi, Menimbang Bayi.

3. Aspek Ekonomi

a. Pemberian Inovasi Baru Terhadap Masyarakat

Kegiatan ini bertujuan memberikan inovasi kepada masayarakat sekitar terutama kepada ibu-ibu yang tidak memiliki kegiatan atau dengan kata lain ibu rumah tangga untuk membuka peluang usaha yang akan mengahasilkan rupiah dengan membuat usaha rumahan seperti yang kami sarankan untuk membuat usaha membuat kue.

\section{b. Tabungan Usia Dini}

Kegiatan Tabungan Usia Dini ini Di Kp. Monggor Kemang bertujuan agar.

- Mengajari anak-anak untuk mengelola keuangan

- Mengenalkan perbankan melalui tabungan

- Menjadikan Anak-anak memiliki kebiasaan menabung.

4. Aspek Hukum

a. Penyuluhan tentang hukum Membangun kesadaran hukum terhadap perlindungan anak dan pemberdayaan perempuan “ Kegiatan ini bertujuan untuk memberi pemahaman hukum kepada warga desa sekecamatan cigudeg terhadap anak dan perempuan atas kasus yang terjadi berbagai desa yaitu adanya KDRT dan hamil diluar nikah. Pentingnya sosialisasi UU Perlindungan anak.

\section{Aspek Teknik}

\section{a. Gapura}

Bertujuan untuk membuat Icon baru di Kampung Monggor Kemang.

b. Pengecatan Mushola

Kegiatan ini bertujuan memberikan kenyamanan dan kelayakan kepada jamaah danwarga ketika menggunakan Menggunakan Mushola tersebut.

c. Penerangan Jalan

Kegiatan memberikan papan nama jalan bertujuan untuk memudahkan masyarakat luar yang datang kesana tidak sulit untuk sampai ke tempat tujuannya. 


\section{REFERENSI}

(2018). Petunjuk Pelaksanaan KKN Tematik Terintegrasi 2018 Universitas Ibn KhaldunBogor. Bogor: UIKA Press.

Internet:

http://www.kompasiana.com/nyaiendit/me mbangun-sebuah-taman-bacaanmasyarakat_5516fd07a33311f17a $\underline{\mathrm{ba} 7 \mathrm{fc} 3}$

http://pkm.uikabogor.ac.id/index.php/ABDIDOS/iss ue/archive

Bahari. (2010). Toleransi Beragama Mahasiswa (Studi tentang Pengaruh Kepribadian, Keterlibatan Organisasi, Hasil Belajar Pendidikan Agama, dan Lingkungan Pendidikan terhadap Toleransi Mahasiswa Berbeda Agama pada 7 Perguruan Tinggi Umum Negeri. Jakarta: Kementerian Agama RI Badan Litbang dan Diklat Puslitbang Kehidupan Keagamaan.

Gall, M.D., Gall, J.P. dan Borg,W.R. (2003). Educational Research an Introduction. Boston: Pearson Education, Inc. Joyce, Bruce dan Weil, Marsha. (1996). Models of Teaching. Boston: Allyn and Bacon.
Kusumadewi,L.R. (1999). Sikap dan Toleransi Beragama di Kalangan Mahasiswa: Studi di Tiga Perguruan Tinggi di Jakarta. Skripsi. Depok: FISIP UI.

Pelaporan Pedoman PPM Universitas Ibn Khaldun Bogor. 2017

Slavin, R.E. (2005). Cooperative learning: theory, research and practice. London: Allyn and Bacon.

Talib, A. T dan Gill, S.S. (2012). Socioreligious tolerance: exploring the Malaysian experience. Global Journal of Human Social Science. 12(8). 49-54.

Tim Penyusun. (2008). Toleransi dalam Pasungan: Pandangan Generasi Muda terhadap Masalah Kebangsaan, Pluralitas dan Kepemimpinan Nasional. Jakarta:SETARA Institute.

Tim Peneliti. (2006). Laporan Hasil Survei Pengetahuan, Sikap dan Perilaku Stakeholders terhadap Organisasi Masyarakat Sipil. Jakarta: LP3ES dan YAPPIKA. 